Acta Poetica 28 (1-2)

PRIMAVERA-OTOÑO

2007

\title{
"Relaciones peligrosas". Walter Benjamin y Carl Schmitt en el crepúsculo de Weimar
}

\author{
Enzo Traverso
}

\begin{abstract}
Enzo Traverso investiga la relación entre Walter Benjamin y Carl Schmitt en el contexto de la crisis europea de la década de los treinta. Benjamin consagró a Schmitt algunos pasajes de su libro sobre el drama barroco alemán (1928) y en 1930 le escribió una carta en la cual subrayaba sus afinidades con el teórico de la dictadura y del "decisionismo". Este último no contestó pero conservó la carta que se convirtió en la base de sus debates con el filósofo judío-alemán Jakob Taubes después de la Guerra. Traverso reconoce la imposibilidad de un diálogo entre la forma revolucionaria del mesianismo judío defendida por Benjamin y la forma conservadora de teología política elaborada por Schmitt. Ambos compartían una misma visión de la historia como catástrofe y reivindicaban la necesidad de una decisión política, pero sus terapias eran radicalmente contrapuestas: Benjamin identificaba el advenimiento de la era mesiánica con la revolución proletaria, mientras que Schmitt acogía el nazismo como una especie de moderno katechon (el vencedor del Anticristo en la tradición católica).
\end{abstract}

Enzo Traverso analyzes the relationship between Walter Benjamin and Carl Schmitt in the context of the European crisis of the 1930s. Benjamin devoted to Schmitt several passages of his book on German Trauerspiel (1928) and in 1930 wrote a letter to him, where he emphasized his affinities with the theoretician of the Dictatorship and "Decisionism". The latter did not respond but conserved this letter, which was the basis of his discussions with the Jewish-German Philosopher Jakob Taubes after the II World 
War. Traverso underlines the impossibility of a dialogue between the revolutionary form of Jewish Messianism defended by Benjamin and the conservative form of Political Theology elaborated by Schmitt. Both shared the vision of History as a growing catastrophe and claimed the necessity of a political decision, but their therapies were radically opposed: Benjamin identified the coming of the Messianic era with the proletarian revolution, whereas Schmitt welcomed Nazism as a sort of modern Katechon (the defeater of anti-Christ in the Catholic tradition). 
Acta Poetica 28 (1-2)

PRIMAVERA-OTOÑO

2007

Enzo Traverso

Universidad de Amiens, Francia

Traducción: Esther Cohen

"Relaciones peligrosas". Walter Benjamin y Carl Schmitt en el crepúsculo de Weimar ${ }^{1}$

El clima turbulento de la posguerra polariza el campo intelectual creando figuras paradójicas de "revolucionarios conservadores", estableciendo diálogos sorprendentes, condenados inevitablemente al naufragio entre pensadores antitéticos. Dígase inmediatamente que no se trata de una coincidentia oppositorum, como pretenden los críticos liberales del totalitarismo, siempre atentos a considerar los síntomas de un "fascismo rojo" y de un "bolchevismo pardo": los extremos no se tocan. Fascismo y comunismo no convergen, pero su oposición puede partir de un balance condividido: la crisis europea, el derrumbe definitivo del viejo orden político y la necesidad de encontrar una solución radical para el futuro. La edad del constitucionalismo y de la liberación parece terminada, arrollada por una oleada devastadora; las únicas características re-

\footnotetext{
${ }^{1}$ Este texto se extrajo de un capítulo de un libro sobre el concepto de la guerra civil europea, publicado en francés (A feu et à sang. De la guerre civile européenne 1914-1945, Paris, Stock, 2007) y de próxima aparición en español.
} 
conocibles del nuevo orden que se está perfilando son aquellas del nihilismo. En este contexto se sitúa el "diálogo" naufragado incluso antes de haber nacido, entre Benjamin y Schmitt. Nafta no puede más sustraerse a una elección política. El héroe de La montaña mágica parece poseer diversos caracteres del crítico de arte berlinés y del jurista católico renano. Thomas Mann lo describe como un filósofo apocalíptico al mismo tiempo que revolucionario y reaccionario, judío ortodoxo convertido al catolicismo y formado en la enseñanza jesuita, socialista romántico y admirador de la Contrarreforma, detractor del progreso y profeta de la catástrofe, por lo cual revolución y reacción encuentran un punto de coincidencia en la disolución del mundo secularizado encarnado por el capitalismo y por la reorganización de la sociedad según un modelo comunista. Nafta preconiza la "dictadura del proletariado, esta sana exigencia político-económica de nuestros tiempos", en la cual ve una nueva forma de Dios; "su tarea es el terror para la salvación del mundo, para alcanzar la meta de salvación, la filiación divina sin estado y sin clases". ${ }^{2}$

Fue Benjamin quien se puso en contacto con Schmitt en diciembre de 1930 a través de una carta en la que le anunciaba el envío de su libro sobre el drama barroco alemán. Su interés por el filósofo del derecho, católico y reaccionario, no sorprende en un intelectual que había prestado siempre gran atención al pensamiento de la derecha, desde Hofmannsthal hasta Klages, de George hasta Jouhandeau. De acuerdo con Scholem, que recuerda su amistad con el futuro filósofo nazi Hans Heyse, en Munich, hacia el final de la Gran Guerra, Benjamin sabía captar "el rumbo subterráneo de la revolución incluso en autores cuya concepción del mundo denuncia características destacadamente reaccionarias" y manifestaba una gran sensibilidad frente a la más "extraña influencia recíproca entre la

\footnotetext{
2 Thomas Mann, La montagna magica, Milan, Dall'Oglio, 1930, vol. II, p. 68 (edición original, Der Zauberberg. Roman [1924], Frankfurt am Main, Fischer, 2000).
} 
teoría reaccionaria y la práctica revolucionaria". ${ }^{3}$ En una carta de 1934 a Gretel Karplus —-futura esposa de Adorno-, confesaba que su vida y su pensamiento se "movían en posiciones extremas", tomando forma gracias a la yuxtaposición de puntos de vista antinómicos que sus amigos percibían solamente como "relaciones peligrosas [gefährliche Beziehungen]". 4

En su libro sobre el Trauerspiel, él precisaba en su carta a Schmitt que debía mucho a los escritos del jurista renano, en particular a la Teología política (1921) y a La dictadura (1922), y sus investigaciones sobre la historia del arte no hacían más que confirmar los postulados subyacentes a la "filosofía del Estado" de Schmitt. ${ }^{5}$ Este último no respondió pero conservó la carta que evocará más tarde en un ensayo sobre Shakespeare constelado de referencias al Trauerspielbuch. ${ }^{6}$ ¿En qué consiste esta afinidad entre dos autores tan diferentes de la cual Jacob Taubes, uno de los primeros comentadores de esta carta que se mantuvo largo tiempo oculta -Adorno y Scholem decidieron no incluirla en la primera edición de la correspondencia de Benjamin—, tenía la impresión de captar una de las "constelaciones más prometedoras de la república de Weimar"?7 Tratemos de explorar este lazo insólito y paradójico.

\footnotetext{
3 Gershom Scholem, "Walter Benjamin" [1965], en Walter Benjamin y su ángel, Buenos Aires, FCE, 2003, pp. 106-107 (edición original, Über Walter Benjamin, Frankfurt am Main, Suhrkamp, 1968). Sobre su amistad en relación con Hans Heyse, cf. Gershom Scholem, Walter Benjamin. Historia de una amistad, p. 99.

${ }^{4}$ Cf. Walter Benjamin, Gesammelte Briefe, Bd. IV, Frankfurt am Main, Suhrkamp, 1998, p. 441. Véase también de Susanne Heil, Gefährliche Beziehungen. Walter Benjamin und Carl Schmitt, Stuttgart, Metzler, 1996, p. 4, que ha reconstruido las relaciones entre los dos filósofos.

${ }^{5}$ Walter Benjamin, Gesammelte Briefe, Bd. III, Frankfurt am Main, Suhrkamp, 1997, p. 558.

${ }^{6}$ Cf. Carl Schmitt, Hamlet oder Hekuba. Der Einbruch der Zeit in das Spiel, Stuttgart, Clett-Kotta, 1985.

7 Jacob Taubes, In divergente accordo. Scritti su Carl Schmitt, introducción de Eletta Stimilli, Macerata Quodlibet, 1996, p. 37 (edición original, Ad Carl Schmitt. Gegenstrebige Fügung, Berlin, Merve Verlag, 1987).
} 
En sus escritos de los primeros años veinte, Schmitt había teorizado la dictadura como régimen que implicaba el "estado de excepción" (Ausnahmezustand). La suspensión del estado de derecho, con la restricción de las libertades individuales y la puesta en discusión de algunas libertades fundamentales, podía ser una medida transitoria en la perspectiva de preservar el estado y de restablecer el derecho o, entonces, tratándose del poder constituyente de las dictaduras modernas, con la mira de instaurar un nuevo orden legal. ${ }^{8}$ En "Teología política", el estado de excepción está ligado a un poder "de decisión" sobre el cual se apoya, desde su perspectiva, el fundamento último de la soberanía. Según la fórmula que abre su libro, el soberano tiene el poder de instaurar el "estado de excepción". 9 A diferencia del dictador tradicional, sujeto a la ley, dotado de un poder delegado y transitorio, el soberano definido por Schmitt dispone de un poder absoluto y autónomo, sin límites; siguiendo la genealogía del concepto de soberanía, él recoge los orígenes del absolutismo, fruto de una secularización de la teología política a través de la cual el soberano se sustituye por Dios. Los primeros pasos de esta vía habían sido realizados por Bodin, pero es Hobbes el autor que, según Schmitt, cumple el pasaje de la teología a la concepción moderna de la soberanía, teorizando al estado como un Leviatán, al mismo tiempo legislador y detentador de la fuerza —en términos weberianos, Herrschaft y Macht — que exige sumisión y obediencia de parte de sus súbditos.

En comparación con la iglesia que funda su legitimidad en la fe de sus discípulos aun antes que en sus normas prefijadas y cuya acción adquiere impulso de un Dios omnipotente más que de la simple aplicación de la ley, el poder soberano

\footnotetext{
${ }^{8}$ Carl Schmitt, Die Diktatur [1921], Berlin, Duncker \& Humblot, 1989.

9 Carl Schmitt, "Teologia politica”, en Le categorie del politico, Bologna, Il mulino, 1972, p. 83 (edición original, Politische Theologie, Berlin, Duncker \& Humblot, 1985).
} 
bosquejado por Schmitt no se somete a ninguna autoridad superior, porque posee en sí mismo los recursos de la propia legitimidad. En el contexto de la naciente República de Weimar, y más aún en 1930, al inicio de su agonía, este elogio de la decisión soberana irrevocable suena como un llamado a la dictadura, de la cual reclama la instauración recurriendo al artículo 48 de la Constitución. Se trata para Schmitt de reivindicar un poder legítimo capaz de superar la parálisis de una democracia cerrada en la legalidad de sus instituciones parlamentarias y lacerada por sus conflictos internos, incapaz de generar un ejecutivo estable y, por lo tanto, condenada a la impotencia. La decisión se opone a la norma y al debate público, dos elementos constitutivos de la tradición liberal representada entonces por Hans Kelsen (una tradición de la cual Schmitt habría indicado enseguida, en diferentes escritos con una fuerte connotación antisemita, las raíces judías desde Spinoza a Mendelssohn y Stahl). ${ }^{10}$ Este llamado a la decisión en contra del parlamentarismo se inscribe en una tradición antiliberal bien precisa, la de los filósofos católicos de la Contrarrevolución, Joseph de Mastre y Donoso Cortés, quienes habían captado la alternativa fundamental dada por los terribles acontecimientos de 1789 y de 1848: catolicismo o ateísmo, absolutismo o socialismo. ${ }^{11}$ El liberalismo no está más a la altura de una época que reclama otra elección decisiva: Revolución o Contrarrevolución, socialismo o estado total. En sus escritos de los años veinte, como ya hemos visto, Schmitt establece las premisas teóricas de su futura adhesión al nazismo.

\footnotetext{
10 Ver en particular de Carl Schmitt, "Il Leviatano nella doctrina dello stato di Thomas Hobbes. Senso e fallimento di un simbolo politico", en Scritti su Thomas Hobbes, Milano, Giuffrè, 1986, pp. 118-119 (edición original, Der Leviathan in der Staatslehre des Thomas Hobbes. Sinn und Fehlschlag eines politischen Symbol, Stuttgart, Clett-Kotta, 1993). Sobre el antisemitismo de Schmitt, $c f$. Raphael Gross, Carl Schmitt und die Juden, Frankfurt am Main, Suhrkamp, 2000.

${ }^{11}$ Cf. Carl Schmitt, "Teologia politica”, pp. 75 ss.
} 
En su libro sobre el Trauerspiel (1925), Benjamin interpreta el nacimiento de la alegoría barroca, con sus imágenes de soberanos melancólicos y lacerados por insuperables dilemas, como el reflejo estético de una edad en crisis. Contrariamente al Renacimiento, una época de plenitud cultural dominada por un ideal de armonía en un contexto favorable al desarrollo de las ciencias y de las artes, la edad barroca está dominada por la crisis. Sus héroes son invadidos por el sentimiento de una catástrofe inminente, como si fueran empujados hacia una "catarata". ${ }^{12}$ La tempestad interior que agita permanentemente a los soberanos representados de esta forma de arte es obviamente una consecuencia de su época de calamidad, pero los dilemas que los atormentan no encuentran solución. El héroe del Trauerspiel es, sí, el príncipe que, como el Leviatán de Hobbes, "tiene el curso de la historia en sus manos como un cetro", pero su drama está en el hecho de que encarna una soberanía ya vacía. Deriva entonces de su impotencia, del hecho que aun siendo el detentador, en cuanto príncipe, del "poder ejecutivo supremo", es decir, el poder de promulgar "el estado de excepción", ${ }^{13}$ las situaciones en las cuales se encuentra constantemente involucrado prueban que no tiene más la capacidad de decidir. ${ }^{14}$ Benjamin toma prestado de Schmitt sus categorías (soberanía, decisión, estado de excepción), pero invierte la perspectiva. Traza un perfil de la edad barroca en cuyo centro no gobierna más el Leviatán omnipotente de Hobbes, sino un conjunto de figuras trágicas que, como Hamlet, quedan prisioneras de sus dilemas y son, por lo tanto, incapaces de actuar, poseídas por un destino cruel que las condena a

\footnotetext{
12 Walter Benjamin, Il dramma barocco tedesco, Torino, Einaudi, 1971, p. 53 (edición original, Ursprung des deutschen Trauerspiels, Frankfurt am Main, Suhrkamp, 1963. Existe tradución al español, "El Origen del Trauerspiel alemán", en Walter Benjamin, Obras, libro I, volumen 1, Madrid, Abada Editores, 2006, pp. 217-449).

${ }^{13}$ Ibid., p. 52.

14 Ibid., p. 59.
} 
ser no los príncipes amados sino los tiranos o los mártires. Si para Schmitt el estado de excepción deriva de su decisión última y vinculante del soberano como antítesis de la incertidumbre y de la discusión pasiva, para Benjamin, al contrario, eso parece designar un estado de crisis permanente. Giorgio Agamben observa con pertinencia una separación profunda entre una visión de la decisión como "milagro" restaurador que une soberanía y excepción, y una visión del estado de excepción como catástrofe. ${ }^{15}$ Sin embargo, es necesario agregar que esta escisión se profundiza hasta convertirse en algo insuperable, cuando Benjamin interpreta esta catástrofe a la luz del mesianismo judío, atribuyéndole las características de una Apocalipsis redentora. En la visión del mundo barroco, escribe, "todo lo que es terrestre se precipita transformándose en un campo de despojos"; pero esta caída representa también una "alegoría de la resurrección". ${ }^{16}$ Gracias a la transfiguración barroca de la muerte, el infierno se cambia con un sortilegio dialéctico en el "mundo divino"; la caída lleva en sí las premisas de una redención que, según las palabras de un poema de Lohenstein, dará al fin un rostro de ángel a una "calavera [Totenkopf]". ${ }^{17}$

Al decisionismo de Schmitt corresponde ahora el nihilismo mesiánico de Benjamin. En su ensayo intitulado "Por una crítica de la violencia" (1921), el joven crítico berlinés se había inspirado en Sorel -otra figura de frontera, a mitad de camino entre marxismo y fascismo - para teorizar una violencia no más restauradora del orden y de la ley, sino "divina" [göttliche Gewalt], destructora del derecho, irreductible a cualquier vínculo exterior. ${ }^{18}$ Él consideraba en esta violen-

\footnotetext{
15 Giorgio Agamben, Stato di eccezione, Torino, Bollati Boringhieri, 2003, p. 73 (existe traducción al español en Pre-Textos).

${ }^{16}$ Walter Benjamin, Il dramma barocco tedesco, p. 253.

${ }^{17}$ Ibid.

18 Walter Benjamin, "Zur Kritik der Gewalt" [1921], en Angelus Novus. Ausgewählte Schriften II, Frankfurt am Main, Suhrkamp, 1977, pp. 62-63 (traducción ita-
} 
cia "pura", "sin límites" y anómica, una dimensión "revolucionaria", la "suprema dimensión de violencia pura por parte del hombre". ${ }^{19}$ Esta violencia presentaba un doble rostro, al mismo tiempo teológico y político: teológico, ya que hacía irrupción en la escena de la historia, rompiendo su continuidad como un Apocalipsis redentor; y político, a causa de su naturaleza revolucionaria, análoga a la "huelga general" de Sorel que destruye el orden burgués y crea uno nuevo, proletario. En un ensayo escrito probablemente en la misma época, "Fragmento teológico-político", uno de sus textos más oscuros y enigmáticos, Benjamin atribuía a esta violencia, al mismo tiempo divina y revolucionaria, las características del nihilismo. ${ }^{20}$

Esta violencia se sitúa en las antípodas del estado de excepción de Schmitt, prerrogativa de un poder soberano tendiente a preservar o restablecer el orden. De hecho, es justamente en contra de esta violencia redentora como el jurista católico reclama un estado de excepción. En los años treinta, él desentierra el concepto católico (de origen paulino) de katechon, que interpreta al imperio cristiano como un poder "frenante" (qui tenet), o sea una fuerza en grado de impedir el advenimiento del Anticristo y de permitir, en esta prórroga arrancada al poder del mal, el desarrollo de la historia. Entre el medioevo cristiano y el siglo veinte, esta fuerza ha conocido, según Schmitt, múltiples encarnaciones. Ella resurge en el momento en que reaparece el Anticristo, primero bajo el disfraz de la civilización mecánica del occidente secular, después bajo aquellas extremas del comunismo ateo. "La fe en una "fuerza frenan-

liana, "Per la critica della violenza", en Angelus Novus. Saggi e frammenti, Torino, Einaudi, 1982, p. 26. Existe traducción al español, "Por una crítica de la violencia", en Iluminaciones I, Madrid, Taurus, 1998).

${ }^{19}$ Ibid., p. 66 (traducción italiana, p. 29).

20 Walter Benjamin, "Theologisch-politisches Fragment", en Angelus Novus. Ausgewählte Schriften II, Frankfurt am Main, Suhrkamp, 1977, p. 263. 
te" capaz de detener el fin del mundo - escribe Schmitt en $E l$ nomos de la tierra (1951) — gesta los únicos puentes que de la parálisis escatológica de todo acontecer humano conducen a una grandiosa potencia histórica como aquella del imperio cristiano de los reyes germánicos". ${ }^{21}$

La figura del Anticristo habita también los escritos de Benjamin, en particular sus Tesis de la Filosofía de la Historia de 1940. Es cierto que el recurso de esta imagen de la teología cristiana en el seno de un texto completamente bañado de mesianismo judío constituye una de las numerosas sorpresas a las cuales se expone el lector de Benjamin, pero el sentido de esta metáfora no presenta ambigüedades. La sexta Tesis que invoca las imágenes del pasado, que resurgen "en el instante del peligro", cuando "la clase dominante" amenaza ganar una victoria definitiva y destruir con su violencia la tradición y la memoria de los vencidos, ve en el Mesías no solamente al "redentor", sino también al "vencedor del anticristo". ${ }^{22}$ Un estudio genealógico de esta tesis parece indicar que la referencia al Anticristo ha sido tomado de Fritz Lieb, un teólogo protestante de origen suizo y de orientación socialista con el cual Benjamin había establecido relaciones de amistad y un fructuoso intercambio intelectual. Desde 1934, Lieb había presentado al nazismo como una versión moderna y secular del Anticristo, atribuyendo así a la lucha antifascista una fuerte dimensión religiosa. Para Benjamin, el proletariado, el sujeto histórico en

\footnotetext{
${ }^{21}$ Carl Schmitt, Der Nomos der Erde im Völkerrecht des Jus Publicum Europaeum, Berlin, Duncker \& Humblot, 1951, p. 29 (traducción italiana, Il nomos della terra nel diritto internazionale dello "jus publicum europaum”, Milano, Adelphi, 1991, p. 44).

22 Sobre el concepto de katechon en Schmitt, cf. Christian Meier, The Lesson of Carl Schmitt. Four Chapters in the Distinction Between Political Theology and Political Philosophy, Chicago, The University of Chicago Press, 1998, pp. 160167; Raphael Gross, Carl Schmitt und die Juden, pp. 284-301; y Horst Bredekamp, "From Walter Benjamin to Carl Schmitt, via Thomas Hobbes", en Critical Inquiry, 25:2, 1999, pp. 252-254.
} 
la lucha contra el nazismo, debía comprender el alcance teológico de este choque apocalíptico ya que el enemigo, el régimen nazi, no dudaba en presentarse como una promesa de salvación en una especie de nuevo reino milenario. ${ }^{23}$

Estamos entonces ante la presencia, en Benjamin y Schmitt, de dos teologías políticas: una judía, la otra católica; una revolucionaria y mesiánica, la otra conservadora y ultramundana. Para ambas, el Anticristo encarna al enemigo, pero por principio toma la forma del nazismo y, en segundo lugar, la del bolchevismo ateo. La primera preconiza el advenimiento del Mesías - la ruptura del continuum de la historia - que identifica con la revolución proletaria; la segunda hace un llamado al katechon en la forma de un poder absoluto decisionista. La primera ve en la revolución la forma concreta del Apocalipsis, o sea, el pasaje del tiempo histórico del presente al tiempo mesiánico del futuro; ${ }^{24}$ la otra ve en el katechon el vínculo indispensable entre la escatología cristiana y la vida del catolicismo en un mundo secularizado. ${ }^{25}$ Estas dos teologías políticas chocan sobre la base de un diagnóstico compartido - la crisis del presente, la necesidad de tomar una decisión de salir de ella- que está formulado a través de las mismas categorías

\footnotetext{
23 Bajo la influencia de Lieb por la adopción de la imagen del anticristo por parte de Benjamin, $c f$. Chryssoula Kambas, "Actualité politique. Le Concept d'histoire chez Benjamin et l'échec du Front populaire”, en Heinz Wismann (ed.), Walter Benjamin et Paris, Paris, Éditions du Cerf, 1986, pp. 277-284; y Michael Löwy, Walter Benjamin: avertissement d'incendie. Une lecture des thèses "Sur le concept d'histoire”, Paris, Presses universitaires de France, 2001, pp. 53-54 (existe traducción al español en FCE).

24 Véase la definición del apocalipsis sugerida por Gershom Scholem, "Zum Verständnis der messianischen Idee im Judentum", en Über einige Grundbegriffe des Judentums, Frankfurt am Main, Suhrkamp, 1970, p. 130.

25 En las páginas de su diario de 1947, Schmitt escribe: "creo en el katechon, que para mí representa la única posibilidad de comprender la historia como cristiano y encontrarla sensata" (Glossarium. Aufzeichnungen der Jahre 1947-1951, Berlin, Duncker \& Humblot, p. 63; traducción italiana: Glosario, Milano, Giuffrè, 2001, p. 91.
} 
analíticas, pero que desemboca en dos terapias políticas del todo opuestas: Revolución y Contrarrevolución. ${ }^{26}$

La carta de Benjamin a Schmitt de septiembre de 1930 no tuvo respuesta. Si su diálogo parecía aún posible en 1930, la llegada al poder de Hitler, tres años después, había excavado una brecha insuperable. Para Benjamin, el nihilismo esbozado en sus escritos de inicio de los años veinte, tomaba las formas del marxismo, ciertamente un marxismo incatalogable, bañado de acentos mesiánicos y decididamente antipositivista, pero dotado de un perfil político coherente. La teoría política de Schmitt encontraba un anclaje político en el nazismo. En la octava de sus Tesis de 1940, Benjamin hacía una última alusión a Schmitt, recordando la "tradición de los oprimidos" por los cuales el "estado de excepción" (escrito entre comillas) se ha convertido en "la regla". Para poner fin al continuum catastrófico de la historia, que se despliega como un cortejo triunfal e ininterrumpido de vencedores, él proponía instaurar el "verdadero estado de excepción" (wirkliche Ausnahmezustand), el único capaz de llevar a término la lucha contra el fascismo, es decir, la revolución. ${ }^{27}$ Benjamin usaba también, tomando las distancias necesarias, los conceptos de Schmitt, pero, como subraya Taubes, lo hacía plenamente consciente de haberlos "acogido e invertido en su contrario". ${ }^{28}$ Lejos de ser un ejemplo de coincidentia oppositorum, la relación entre Benjamin y Schmitt ilustra la polarización ejercida por la Guerra civil europea en el campo intelectual en los años entre las dos guerras.

\footnotetext{
${ }^{26}$ Cf. Ricardo Forster, "El estado de excepción: Benjamin y Schmitt como pensadores del riesgo", en Jorge Dotti, y Julio Pinto, (eds.), Carl Schmitt. Su época y su pensamiento, Buenos Aires, Eudeba, 2002, p. 131.

${ }^{27}$ Walter Benjamin, "Über den Begriff der Geschichte”, en op. cit., pp. 254-255 (traducción italiana, "Tesi di filosofia della storia", en op. cit., p. 79, ligeramente modificada).

${ }^{28}$ Jacob Taubes, In divergente accordo, p. 38.
} 
El año de 1933 constituye un verdadero y propio parte aguas en el seno de la cultura política alemana. No señala solamente la ruptura entre Heidegger y sus discípulos de la izquierda, de Marcuse a Anders, sino también entre Schmitt y sus discípulos de la izquierda, también ellos judíos, como Franz Neumann y Otto Kirchheimer. Estos últimos habían creído captar una convergencia, en la teoría política de Schmitt, con la crítica marxista de la visión liberal del Estado como entidad "neutral", que identifica legalidad y legitimidad con un poder político separado de la sociedad y situado por encima de la lucha de clases. En esta perspectiva, la Zeitschrift für Sozialforschung, la revista de la Escuela de Frankfurt, había publicado comentarios favorables a los escritos de Schmitt, apreciando sobre todo su visión de lo político como esfera del conflicto. ${ }^{29} \mathrm{El}$ malentendido fue aclarado rápidamente. En 1934, Marcuse procedía en la misma revista a una verdadera y propia demolición del existencialismo político alemán, del cual tomaba la expresión más significativa en el discurso del rectorado de Heidegger y en las tesis de Schmitt sobre el estado total. ${ }^{30}$ Por su parte, Kirchheimer tomaba distancia frente a Schmitt observando que su crítica del liberalismo no desembocaba en la defensa de la democracia sino en la apo-

\footnotetext{
${ }^{29}$ Cf. en particular Karl Korsch, "Carl Schmitt, Der Hüter der Verfassung", en Zeitschrift für Sozialforschung, vol. I, 1932, pp. 204-205. Sobre la influencia ejercida por el pensamiento de Schmitt sobre algunos miembros de la Escuela de Frankfurt, $c f$. Ellen Kennedy, "Carl Scmitt and the Frankfort School", en Telos, número 71, 1987, pp. 37-66; y Alfons Söllner, "Disciples de gauche de la Révolution conservatrice. La théorie politique d'Otto Kirchheimer et de Herbert Marcase dans les dernières années de la République de Weimar", en Gérard Raulet (ed.), Weimar ou l'explosion de la modernité, Paris, Anthropos, 1984, pp. 113-128.

${ }^{30}$ Herbert Marcuse, "La lotta contro il liberalismo nella concezione totalitaria dello stato" [1934], en Cultura e società. Saggi di teoria critica 1933-1965, Torino, Einaudi, 1969, pp. 3-41 (edición original, "Der Kampf gegen den Liberalismus in der totalitären Staatsauffassung", en Kultur und Gesellschaft, Frankfurt am Main, Suhrkamp, 1965). Sobre el cambio señalado por este ensayo en la relación entre la Escuela de Frankfurt y Schmitt, $c f$. Ellen Kennedy, "Carl Schmitt and the Frankfort School", p. 54.
} 
logía de una dictadura plebiscitaria. ${ }^{31}$ Todos consideraban la crítica a la obra de Schmitt como una etapa obligada. En este sentido, Mario Tronti tiene probablemente razón cuando afirma que "en el Novecento Marx incorporó a Schmitt".32

\section{BIBLIOGRAFÍA}

Agamben, Giorgio, Stato di eccezione, Torino, Bollati Boringhieri, 2003 (existe traducción al español en Pre-Textos).

Benjamin, Walter, Il dramma barocco tedesco, Torino, Einaudi, 1971 (edición original, Ursprung des deutschen Trauerspiels, Frankfurt am Main, Suhrkamp, 1963. Existe tradución al español, "El Origen del Trauerspiel alemán", en Walter Benjamin, Obras, libro I, volumen 1, Madrid, Abada Editores, 2006).

— "Theologisch-politisches Fragment", en Angelus Novus. Ausgewählte Schriften II, Frankfurt am Main, Suhrkamp, 1977.

_ "Zur Kritik der Gewalt" [1921], en Angelus Novus. Ausgewählte Schriften II, Frankfurt am Main, Suhrkamp, 1977 (traducción italiana, "Per la critica della violenza", en Angelus Novus. Saggi e frammenti, Torino, Einaudi, 1982. Existe traducción al español, "Por una crítica de la violencia", en Iluminaciones I, Madrid, Taurus, 1998).

- Gesammelte Briefe, Bd. III, Frankfurt am Main, Suhrkamp, 1997.

- Gesammelte Briefe, Bd. IV, Frankfurt am Main, Suhrkamp, 1998.

BredeKamp, Horst, "From Walter Benjamin to Carl Schmitt, via Thomas Hobbes", en Critical Inquiry, 25:2, 1999.

Forster, Ricardo, "El estado de excepción: Benjamin y Schmitt como pensadores del riesgo", en Jorge Dotti, y Julio Pinto

31 Cf. Otto Kirchheimer, Remarks on Carl Schmitt's Legatiy and Legitimacy, (esta crítica de Schmitt conduce la evolución política de Kirchheimer hacia un redescubrimiento del liberalismo clásico).

${ }^{32}$ Mario Tronti, La politica al tramonto, Torino, Einaudi, 1998, p. 155. 
(eds.), Carl Schmitt. Su época y su pensamiento, Buenos Aires, Eudeba, 2002.

Gross, Raphael, Carl Schmitt und die Juden, Frankfurt am Main, Suhrkamp, 2000.

HeIL, Susanne, Gefährliche Beziehungen. Walter Benjamin und Carl Schmitt, Stuttgart, Metzler, 1996.

Kambas, Chryssoula, "Actualité politique. Le Concept d'histoire chez Benjamin et l'échec du Front populaire", en Heinz Wismann, (ed.), Walter Benjamin et Paris, Paris, Éditions du Cerf, 1986.

Kennedy, Ellen, "Carl Schmitt and the Frankfort School", en Telos, número 71, 1987, pp. 37-66.

Korsch, Karl, "Carl Schmitt, Der Hüter der Verfassung”, en Zeitschrift für Sozialforschung, vol. I, 1932.

Löwy, Michael, Walter Benjamin: avertissement d'incendie. Une lecture des thèses "Sur le concept d'histoire", Paris, Presses universitaires de France, 2001 (existe traducción al español, Walter Benjamin: aviso de incendio, Buenos Aires, FCE, 2003).

Mann, Thomas, La montaña mágica, Milan, Dall'Oglio, 1930 (edición original, Der Zauberberg. Roman [1924], Frankfurt am Main, Fischer, 2000).

MARCUSE, Herbert, "La lotta contro il liberalismo nella concezione totalitaria dello stato" [1934], en Cultura e società. Saggi di teoria critica 1933-1965, Torino, Einaudi, 1969 (edición original, "Der Kampf gegen den Liberalismos in der totalitären Staatsauffassung", en Kultur und Gesellschaft, Frankfurt am Main, Suhrkamp, 1965).

MeIER, Christian, The Lesson of Carl Schmitt. Four Chapters in the Distinction Between Political Theology and Political Philosophy, Chicago, The University of Chicago Press, 1998.

Schmiтt, Carl, Der Nomos der Erde im Völkerrecht des Jus Publicum Europaeum, Berlin, Duncker \& Humblot, 1951 (traducción italiana, Il nomos della terra nel diritto internazionale dello “jus publicum europaeum”, Milano, Adelphi, 1991).

— "Teologia politica", en Le categorie del politico, Bologna, Il mulino, 1972 (edición original, Politische Theologie, Berlin, Duncker \& Humblot, 1985). 
Schмiтt, Carl, Hamlet oder Hekuba. Der Einbruch der Zeit in das Spiel, Stuttgart, Clett-Kotta, 1985.

- "Il Leviatano nella doctrina dello stato di Thomas Hobbes. Senso e fallimento di un simbolo politico", en Scritti su Thomas Hobbes, Milano, Giuffrè, 1986 (edición original, Der Leviathan in der Staatslehre des Thomas Hobbes. Sinn und Fehlschlag eines politischen Symbol, Stuttgart, Clett-Kotta, 1993).

— Die Diktatur [1921], Berlin, Duncker \& Humblot, 1989.

- Glossarium. Aufzeichnungen der Jahre 1947-1951, Berlin, Duncker \& Humblot (traducción italiana, Glosario, Milano, Giuffrè, 2001).

Scholem, Gershom, Walter Benjamin y su ángel, Buenos Aires, FCE, 2003 (edición original, Über Walter Benjamin, Frankfurt am Main, Suhrkamp, 1968).

— "Zum Verständnis der messianischen Idee im Judentum”, en Über einige Grundbegriffe des Judentums, Frankfurt am Main, Suhrkamp, 1970

- Walter Benjamin. Historia de una amistad, Barcelona, De Bolsi1lo, 2007.

SöLlnER, Alfons, "Disciples de gauche de la Révolution conservatrice. La théorie politique d'Otto Kirchheimer et de Herbert Marcase dans les dernières années de la république de Weimar", en Gérard Raulet (ed.), Weimar ou l'explosion de la modernité, Paris, Anthropos, 1984.

TAubes, Jacob, In divergente accordo. Scritti su Carl Schmitt, introd. Eletta Stimilli, Macerata Quodlibet, 1996 (edición original, Ad Carl Schmitt. Gegenstrebige Fügung, Berlin, Merve Verlag, 1987).

Tronti, Mario, La politica al tramonto, Torino, Einaudi, 1998. 
